\title{
New data for systematics of the genus Zeravschania (Apiaceae) and related taxa based on the nrDNA (ITS) sequences
}

\author{
Elena Terentieva ${ }^{1 *}$, Uliana Ukrainskaja ${ }^{1}$, Dmitry Lyskov $^{2}$, Tahir Samigullin ${ }^{3}$, and Eugene \\ Kljuykov $^{1}$ \\ ${ }^{1}$ Botanical Garden, Lomonosov Moscow State University, 119234 Moscow, Russia \\ ${ }^{2}$ Lomonosov Moscow State University, 119234 Moscow, Russia \\ ${ }^{3}$ Belozersky Institute of Physico-Chemical Biology, Lomonosov Moscow State University, 119234 \\ Moscow, Russia
}

\begin{abstract}
All 13 species of the genus Zeravschania were studied in molecular and morphological analyzes. The molecular study showed that Zeravschania is a clearly paraphyletic taxon including monotypic genera Demavendia and Haussknechtia. Further phylogenetic, anatomical and morphological studies are needed to confirm taxonomic position of these genera. Zeravschania afghanica confirms its placement in the genus Zeravschania, not in Cephalopodum or Selinum. Dichoropetalum knappii confirms its placement in the genus Dichoropetalum, not in Zeravschania.
\end{abstract}

\section{Introduction}

The genus Zeravschania Korovin (Apiaceae) was described as a monotypic genus with a type species Z. regeliana Korovin distributed in mountainous Central Asia [1]. Seven species were included in Zeravschania from other genera such as Peucedanum L. [2, 3], Eleutherospermum K. Koch [4] and Selinum L. [5]. Five more species were described as new to science: Z. khorasanica Kljuykov \& Lyskov, Z. kopetdaghensis Pimenov \& Kljuykov, Z. latifolia Pimenov \& Kljuykov, Z. podlechii Kljuykov \& Ukrainsk., and Z. scabrifolia Pimenov [2, 6, 7]. All members of the genus are perennial polycarpic plants distributed in Iran, Afghanistan, and Central Asia (Pamir-Alai mountainous region). The greatest diversity of species is founded in northeastern Iran and northern Afghanistan. Zeravschania to date includes 13 species, but nevertheless the question of the genus composition remains debatable. Species of the genus Zeravschania have quite homogeneous morphological features. According to results of molecular studies $[9,10]$ three studied species namely Z. aucheri (Boiss.) Pimenov, Z. membranacea (Boiss.) Pimenov, and $Z$. regeliana form a clade with strong support. Close relationships of Zeravschania and monotypic genera Demavendia Pimenov and Haussknechtia Boiss. were also showed in this study.

\footnotetext{
* Corresponding author: el.terenteva@ mail.ru
} 
The main purpose of our study was to carry out a comparative morphological and molecular analysis of 13 species of Zeravschania and to identify their diagnostic features.

\section{Material and Methods}

Specimens from the following herbaria were revised: E, G, LE, M, MW, TARI, and W. Individual samples were collected by the authors from expeditions to southwest Asia. Some species were represented by two to three samples from different regions.

The set of taxonomically important characters for Apiaceae following was examined Kljuykov et al. [11]. Carpological data are partially taken from previously published materials $[3,6-8,12]$.

As a molecular marker in the molecular-phylogenetic analysis, we have used internal transcribed spacer (ITS) of nuclear ribosomal DNA (nrDNA). DNA extraction, amplification and sequencing the spacers (ITS1, 2) were conducted according to ValiejoRoman et al. [9]. ITS sequences were aligned using MUSCLE 3.6 [13] and then manually adjusted in BioEdit 7.2.5 [14]. Newly obtained sequences were deposited to the GenBank.

Molecular- phylogenetic trees have been obtained by two methods: Bayesian inference (BI) and maximum parsimony (MP) methods. Maximum parsimony analysis was performed using PAUP* version 4.0b08 [15] with TBR branch swapping and equal weighing of characters; gaps were treated as missing data. Bayesian analysis of molecular data was performed using the program MrBayes version 3.2.6 [16].

\section{Results and discussion}

We determined ITS sequences for 27 samples of 13 Zeravschania species. In the molecular-phylogenetic analysis, we additionally included 93 ITS sequences (representing 70 genera) that represent nearly all tribes of subfamily Apioideae. Pleurospermum uralense Hoffm. was used as out-group based on the results of the previous phylogenetic study of the subfamily Apioideae [9]. The emphasis of our samplings focused on the species of Zeravschania plus their closest congeners Demavendia pastinacifolia (Boiss. et Hausskn.) Pimenov, Haussknechtia elymaitica Boiss., Johrenia DC., Dichoropetalum Fenzl and Cephalopodum Korovin which chosen through results of several previous phylogenetic studies $[2-5,8,9]$.

The alignment of 120 ITS sequences resulted in a matrix of 438 positions after excluding ambiguous positions. 93 characters are constant, 46 characters are variable but parsimony-uninformative, and 299 (68\%) characters are parsimony-informative.

Molecular-phylogenetic trees generated by different methods (MP and BI) possessed similar topology, so only a Bayesian tree is provided with indication of posterior probabilities and bootstrap support for the maximum parsimony tree (Fig. 1). 


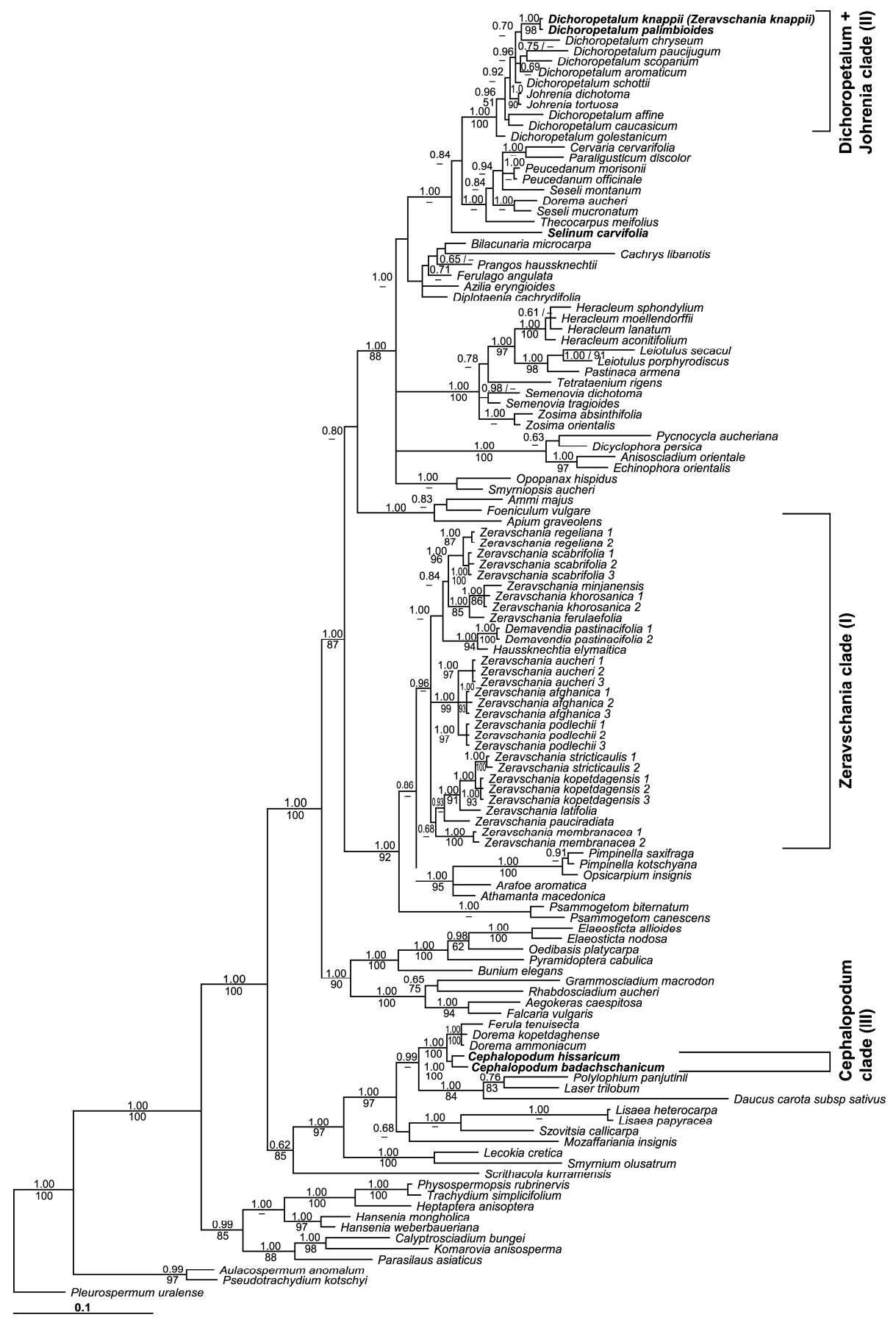

Fig. 1. Consensus tree obtained from Bayesian analysis of nrDNA ITS sequences from 120 accessions (representing 70 genera) of Apiaceae subfamily Apioideae. The tree inferred by Bayesian analysis of these data was highly consistent with the MP strict consensus tree. Bayesian posterior probabilities $\geq 0.95$ are shown above branches. Bootstrap values $>60 \%$ from the parsimony analyses are shown below branches. "-" indicates node not supported in MP analysis. 
The study of the nrITS region shows that all analyzed species of Zeravschania, Demavendia, and Haussknechtia together with critical samples formed a well-supported "Zeravschania" clade (I). All investigated species of Zeravschania are clearly differentiated, each species forming a strongly supported discrete cluster, which is consistent with the results of morphological studies [2, 5-8]. The species of Zeravschania are very similar morphologically, but differ in minor characteristics. Analysis of morphological characters showed that the most important taxonomic characters for the identification species of Zeravschania are as follows: life form (inflorescence form); presence of solid remains of dead leaves at the base of stem; presence of pubescence of stems and leaves; dissection of leaf blades; shape of terminal lobes of leaves; number of rays in umbels (extreme states); length of umbel rays; presence of calyx teeth; color of petals. Shape and number of bracts and bracteoles and fruit features are rather uniform within the genus and are important primarily for the diagnosis of the genus Zeravschania. There is insignificant variability in the shape and size of mericarps, and their ribs. In $Z$. latifolia, a hypoderm of 1-2 layers of small cells is developed under the exocarp. In $Z$. aucheri, the mesocarp consists entirely of lignified cells with porous membranes, while in species Z. afghanica Pimenov, Z. ferulifolia (Gilli) Pimenov and Z. scabrifolia, lignified cells with porous membranes are developed only in the marginal ribs.

The monotypic genera Haussknechtia and Demavendia are placed within the "Zeravschania" clade (I), however these genera pose significant morphological differences from Zeravschania species. Based on morphological data, Pimenov et al. [3] considered that Haussknechtia and Demavendia are better treated as separate monotypic genera. So the genus Zeravschania is not monophyletic, as it was reported previously [3, 9] and we consider Zeravschania as a paraphyletic taxon. Thus, further phylogenetic, anatomical and morphological studies are needed to confirm taxonomic position of Haussknechtia and Demavendia.

The critical sample considered as Demavendia pastinacifolia from East Khorasan (MW), has identical nrITS sequences to Z. stricticaulis (Rech.f.) Pimenov. Thus, the genus Demavendia is distributed only in West and Central Iran [2] and is not found in the East Khorasan.

The species Z. knappii_(Bornm.) Pimenov et Kljuykov included in clade (II) among several species of Dichoropetalum. Zeravschania knappii and Dichoropetalum palimbioides (Boiss.) Pimenov et Kljuykov have nearly identical nrDNA sequences. Thus, this result is in accordance with results of morphological study by Kljuykov et al. [8].

Cephalopodum badachschanicum Korovin and Cephalopodum hissaricum Pimenov form a highly supported monophyletic group (Fig. 1). According nrDNA data the remaining sample of Cephalopodum afghanicum (Rech. f. \& Riedl) Pimenov\&Kljuykov (=Selinum afghanicum Rech. f. \& Riedl) fell into the "Zeravschania" clade is distinct from the members of the "Cephalopodum" clade (III) and Selinum carvifolia Gilib. et DC. (type species), that is accordance with studies by Kljuykov et al. [8] and Degtjareva et.al. [5]. Our results support the taxonomic placement $C$. afghanicum to the genus Zeravschania with a new combination Z. afghanica Pimenov.

The present results are preliminary and have needed further careful morphological, carpological and molecular investigation with another markers (nrDNA, cpDNA).

We thank the curators and staff of mentioned herbaria for the opportunity to examine the material. The reported study was funded by RFBR and INSF, project number 20-5456017.

\section{References}

1. E. P. Korovin, Bot. Mater. Gerb. Inst. Bot. Akad. Nauk Uzbeksk. SSR 12 (1948) 
2. M. G. Pimenov. Flora Iranica, Vol. 162 (Akademische Druk-u Verlagsanstalt, Graz, 1987)

3. M. G. Pimenov, E. V. Kljuykov, T. A. Ostroumova, Willdenowia 37, 2 (2007)

4. K. H. Rechinger, Flora Iranica, Vol 162 (Akademische Druk-u Verlagsanstalt, Graz, 1987)

5. G. V. Degtjareva, T. H. Samigullin, M. G. Pimenov, Botanical J. 104, 3 (2019)

6. M. G. Pimenov Conspectus Flora Asiae mediae, Vol. 7 (Tashkent, 1983)

7. M. G. Pimenov, E. V. Kljuykov, Phytotaxa, 130, 1 (2013)

8. E. Kljuykov, E. Terentieva, U. Ukrainskaja, D. Lyskov, Phytotaxa, 425, 3 (2019)

9. C. M. Valiejo-Roman, E. I. Terentieva, T. H. Samigullin, M. G. Pimenov, F. Ghahremani-Nejad, V. Mozaffarian, Feddes Repert., 177 (2006)

10. Y. Ajani, A. Ajani, J. M. Cordes, M. F. Watson, S. R. Downie. Taxon 57(2) (2008)

11. E. V. Kljuykov, M. Liu, T. A. Ostroumova, M. G. Pimenov, P. M. Tilney, B.-E. van Wyk, S. Afr. J. Bot. 70, 3 (2004)

12. M. G. Pimenov, E. V. Kljuykov, Candollea 57 (2002)

13. R. C. Edgar, Nucleic Acids Res. 32, 5 (2004)

14. T. A. Hall, Nucleic Acids Symp. Ser. 41 (1999)

15. D. L. Swofford, PAUP*. Phylogenetic analysis using parsimony and other methods. Version 4. Sinauer Associates (Sunderland, Massachusetts, 2003)

16. F. Ronquist, M. Teslenko, P. van der Mark, D. L. Ayres, A. Darling, S. Höhna, B. Larget, L. Liu, M. A. Suchard, J. P. Huelsenbeck, Syst. Biol. 61, 3 (2012) 